\title{
Exchange Rate Risk Sharing Contract with Risk-averse Firms
}

\author{
LIU Yang, MA Yong-kai, FU Hong \\ School of Management and Economics, University of Electronic Science and Technology \\ of China, Chengdu, Sichuan 610054, P. R. China
}

\begin{abstract}
In this paper, we consider a global supply chain model which includes a retailer and a manufacturer from different countries. We use a mean-variance model to study how the foreign exchange transaction exposure affects this global supply chain. Furthermore, we design a risk sharing contract to improve the expected utilities of both the node enterprises. Based on our analysis, we find this risk sharing contract can realize the Pareto improvements in this global supply chain when the firms' risk aversion coefficients satisfy some conditions.
\end{abstract}

Keywords: risk-averse; mean-variance model; exchange rate risk; global supply chain.

\section{Introduction}

As a unique risk in the global supply chain, exchange rate risk is one of the most important risks in the global supply chain management ${ }^{[1]}$. Generally, exchange rate risk can be divided into three types, which are the transaction exposure, the account exposure and the operation exposure.

However, to the best of our knowledge, studies on exchange rate risk in the global supply chain are relatively rare. The existing studies on account exposure are mainly focus on firms themselves instead of the global supply chain ${ }^{[2]-[4]}$. The existing literatures has been concerned with operation exposure are mainly aimed at the configuration of the global supply chain networks, but has neglected dealing with the coordination of the global supply chain ${ }^{[5]-[10]}$. The existing studies on transaction exposure in the global supply chain are even rarer. Arcelus studies the newsvendor model ${ }^{[11]}$. Besides, Manuj and Mentzer build a supply chain exchange rate risk frame includes 5 steps [12].

Compared with above studies, our innovations are mainly reflected in the following aspects: (1) We use a supply chain contract instead of financial method or programming to manage the exchange rate risk. (2) Our analysis is based on the 
expected utility, while the existing researches are based on the expected profits.

This paper proceeds as follows: First we set out the assumptions and introduce the basic models. After that, we study the Stackelberg game with risk-averse players. Finally, we design a risk sharing contract to improve this global supply chain.

\section{Model}

We consider a global supply chain includes a retailer in country 1 and a manufacturer in country 2. The manufacturer only supplies one kind of product. The retailer imports this product from the manufacturer at time $T_{0}$ and pays at time $T_{1}$. Here we use a two-stage game to analyze each player's decision. The manufacturer is the leader of this Stackelberg game, while the retailer is the follower. The demand function is $q=a-b p$, in which $a, b>0$, and the production cost $c$ is constant.

For simplicity's sake, let us suppose the exchange rate of country 2's currency relative to the country 1 's currency is $x$. It means $x$ units of country 1's currency equal to 1 unit of country 2's currency. $x$ is a random variable with probability density function $f(x)$ on the support $x \in[A, B]$, in which $0<A \leq B . B$ and $A$ represent the upper and lower limits of $x$. The standard deviations of $x$ is $\delta$ and the variance of $x$ is $\delta^{2}$.
Normally, foreign exchange transaction exposure means uncertain profits. As we assumed above, the manufacturer is dominated in this global supply chain. In order to diminish its transaction exposure, the manufacturer will require the retailer to pay in the currency of country 2 . So the retailer will inevitably meet the foreign exchange transaction exposure.

In order to analyze the influence of foreign exchange transaction exposure, let us suppose both the retailer and the manufacturer are risk-averse players, and their risk aversion coefficients are $\lambda_{R}$ and $\lambda_{M}$. Based on pervious studies ${ }^{[13]-[15]}$, we use the mean-variance model to describe their utilities. Their expected utilities can be represented as:

$$
\left\{\begin{array}{c}
E\left(U_{R}\right)=(a-b p)(p-w E)-\lambda_{R} \sqrt{\operatorname{Var}\left(\Pi_{R}\right)} \\
E\left(U_{M}\right)=(a-b p)(w-c)
\end{array}\right.
$$

The optimal wholesale price of this Stackelberg Game is:

$$
w^{*}=\frac{a+b c\left(x+\lambda_{R} \delta\right)}{2 b\left(x+\lambda_{R} \delta\right)}
$$

The optimal wholesale price is:

$$
p^{*}=\frac{3 a+b c\left(x+\lambda_{R} \delta\right)}{4 b}
$$

The optimal sale quantity is:

$$
q^{*}=\frac{a-b c\left(x+\lambda_{R} \delta\right)}{4}
$$

And their optimal expected profits are: 


$$
\left\{\begin{array}{l}
E\left(U_{R}^{*}\right)=\frac{\left(a-b c\left(E+\lambda_{R} \delta\right)^{2}\right.}{16 b} \\
E\left(U_{M}^{*}\right)=\frac{\left(a-b c\left(E+\lambda_{R} \delta\right)^{2}\right.}{8 b(E+\lambda \delta)}
\end{array}\right.
$$

Theorem 1: (1) When the variation of exchange rate is constant, there is a negative correlation between the expected utilities of both firms and the risk aversion coefficient of the retailer. (2) When the risk aversion coefficient of the retailer is constant, there is a negative correlation between the expected utilities of both firms and the variation of exchange rate.

Proof: In order to facilitate the calculation, we assume $k=E+\lambda_{R} \delta$. Then we have:

$$
\left\{\begin{array}{l}
\frac{\partial E\left(U_{R}^{*}\right)}{\partial k}=-\frac{c(a-b c k)}{8} \\
\frac{\partial E\left(U_{M}^{*}\right)}{\partial k}=-\frac{a^{2}-b^{2} c^{2} k^{2}}{8 b k^{2}}
\end{array}\right.
$$

Based on Eq. (6), it is easy to know that the expected utilities of both firms and $k$ are negative correlated. Which means both the risk aversion coefficient of the retailer $\lambda_{R}$ and the variation of foreign exchange $\delta$ are negative correlated with the expected utilities of both firms.

\section{Risk sharing contract}

From Eq. (4) we know, consider the retailer's risk aversion preference will lead to a reduction in the sale quantity. Here we design a risk sharing contract to increase the sale quantity, thus increasing the expected utilities of both firms. Consider a contract that only require the retailer to pay $1-\theta$ part of the total settlement in the currency of country 2 , and settle the rest part in the currency of country 1 . In this situation, their expected utilities can be represented as:

$\left\{\begin{array}{c}E\left(U_{c R}\right)=(a-b p)\left(p-\left(E-\theta E+\theta+\lambda_{R}(1-\theta) \delta\right) w\right) \\ E\left(U_{c M}\right)=(a-b p)\left(\left(1-\theta+\theta E_{d}-\lambda_{M} \theta \delta_{d}\right) w-c\right)\end{array}\right.$

In which, $E_{d}=\int_{A}^{B} \frac{1}{x} f(x) d x$, stands for the expected exchange rate in manufacturer's realization. Based on the definition of $E_{d}$ and $E$, it is easy to know that $E_{d} E \geq 1$. And $\delta_{d}=\sqrt{\operatorname{Var}\left(\frac{1}{x}\right)}$, stands for the standard deviations of $\frac{1}{x}$. In order to facilitate the calculation, we assume that:

$\left\{\begin{array}{c}y=E-\theta E+\theta+\lambda_{R}(1-\theta) \delta \\ z=1-\theta+\theta E_{d}-\lambda_{M} \theta \delta_{d}\end{array}\right.$

Substituting Eq. (8) into Eq. (7), then we have:

$$
\left\{\begin{array}{l}
E\left(U_{c R}^{*}\right)=\frac{(a z-b c y)^{2}}{16 b z^{2}} \\
E\left(U_{c M}^{*}\right)=\frac{(a z-b c y)^{2}}{8 b y z}
\end{array}\right.
$$

Theorem 2: This risk sharing contract can lead to a Pareto improvement in the performance of this supply chain if $E_{d}-\lambda_{M} \delta_{d}>\frac{1}{E+\lambda_{R} \delta}$ is satisfied.

Proof: Based on Eq. (5) and Eq. (9), after 
the use of this risk sharing contract, the incremental part of their expected utilities can be represented as:

$$
\left\{\begin{array}{c}
E\left(U_{i R}^{*}\right)=\frac{\left(2 a z-b c y-b c z\left(E+\lambda_{R} \delta\right)\left(b c\left(z\left(E+\lambda_{R} \delta\right)-y\right)\right)\right.}{16 b z^{2}} \\
E\left(U_{i M}^{*}\right)=\frac{\left(z\left(E+\lambda_{R} \delta\right)-y\right)\left(a^{2} z-b^{2} c^{2} y\left(E+\lambda_{R} \delta\right)\right)}{8 b y z(E+\lambda \delta)}
\end{array}\right.
$$

Based on Eq. (4), it is easy to know the pre-condition for this deal is $a \geq b c\left(E+\lambda_{R} \delta\right)$. At least one firm will have a negative utility if this condition cannot be satisfied. Hence, the Pareto improvement condition of the supply chain can be transformed into $z\left(E+\lambda_{R} \delta\right)-y>0$.

Substituting Eq. (8) into $z\left(E+\lambda_{R} \delta\right)-y$, then we have:

$$
\begin{aligned}
& z\left(E+\lambda_{R} \delta\right)-y= \\
& \theta\left(E_{d}-\lambda_{M} \delta_{d}-\frac{1}{E+\lambda_{R} \delta}\right)\left(E+\lambda_{R} \delta\right)
\end{aligned}
$$

Based on Eq. (11), the improvement condition of the supply chain can be represented as:

$$
E_{d}-\lambda_{M} \delta_{d}>\frac{1}{E+\lambda_{R} \delta}
$$

\section{Conclusion}

In this paper, we design a risk sharing contract to improve the global supply chain under the foreign exchange transaction exposure. By examining the influences of risk aversion preferences, we draw the following conclusions: (1) There is a negative correlation between the expected utilities of both firms and the risk aversion coefficient of the retailer when the variation of exchange rate is constant; and a negative correlation between the expected utilities of both firms and the variation of the exchange rate when the retailer's risk aversion coefficient is constant. (2) With this risk sharing contract, Pareto improvements can be achieved when their risk aversion coefficients satisfy some conditions.

So far, based on our knowledge, only a few existing studies have investigated the foreign exchange transaction exposure in the global supply chain. And the studies which focused on the risk preferences in the global supply chain are even rarer. For future research, there are some interesting topics. Examples include the coordination of the global supply chain, the risk propensities of firms in the global supply chain.

\section{Acknowledgments:}

We would like to acknowledge the financial support, from the Key Project of the Natural Sciences Foundation (NSF) of china (70932005).

\section{References}

[1] Z. Liu, A. Nagurney, "Supply Chain Outsourcing under Exchange Rate Risk and Competition," Omega, 39(5), pp. 539-549, 2011. 
[2] A. J. Triantis, "Real options and corporate risk management," Journal of Applied Corporate Finance, 13(2), pp. 64-73, 2000.

[3] G. A. Zsidisin, "A grounded definition of supply risk," Journal of Purchasing and Supply Management, 9(5), pp. 217-224, 2003.

[4] P. Liu, T. Wang, "Research on risk evaluation in supply chain based on grey relational method," Journal of computers, 3(10), pp. 28-35, 2008.

[5] S. Dasu, L. Li, "Optimal operating policies in the presence of exchange rate variability," Management Science, 43(5), pp. 705-722, 1997.

[6] M. Goh, J. Lim, and F. Meng, “A stochastic model for risk management in global supply chain networks," European Journal of Operational Research, 182(1), pp. 164-173, 2007.

[7] A. Nagurney, J. Cruz, and D. Matsypura, "Dynamics of global supply chain supernetworks," Mathematical and Computer Modelling, 37(9), pp. 963-983, 2003.

[8] B. Kazaz, M. Dada, and H. Moskowitz, "Global production planning under exchange-rate uncertainty," Management Science, 51(7), pp. 1101-1119, 2005.

[9] A. Huchzermeier, M. A. Cohen, "Valuing operational flexibility under exchange rate risk," Operations research, 44(1), pp. 100-113, 1996.

[10] A. Nagurney, D. Matsypura, “Global supply chain network dynamics with multicriteria decision-making under risk and uncertainty," Transportation Research Part E: Logistics and Transportation Review, 41(6), pp. 585-612, 2005.

[11] F. J. Arcelus, R. Gor, and G. Srinivasan, "Foreign exchange transaction exposure in a newsvendor setting," European Journal of Operational Research, 227, pp. 552-557, 2013.

[12] I. L. Manuj, J. T. Mentzer, "Global Supply Chain Risk Management," Journal of business Logistics, 29(1), pp. 133-155, 2008.

[13] H. S. Lau, A. Lau, "Manufacturer's pricing strategy and return policy for a single-period commodity," European Journal of Operational Research, 116(2), pp. 291-304, 1999.

[14] T. M. Choi, D. Li, and H. Yan, "Mean-variance analysis of a single supplier and retailer supply chain under a returns policy," European Journal of Operational Research, 184(1), pp. 356-376, 2008.

[15] J. Wu, J. Li, and S. Wang, "Mean-variance analysis of the newsvendor model with stockout cost," Omega, 37(3), pp. 724-730, 2009. 